\title{
Recent Advances in Management of Bronchiolitis
}

\author{
Nishant Verma, RaKesh Lodha, S K KabRa \\ From Department of Pediatrics, All India Institute of Medical Sciences, New Delhi 110029, India. \\ Correspondence to: Dr SK Kabra, Department of Pediatrics, AIIMS, New Delhi.skkabra@hotmail.com
}

\begin{abstract}
Background: Bronchiolitis is one of the major causes for hospital admissions in infants. Managing bronchiolitis, both in the outpatient and inpatient setting remains a challenge to the treating pediatrician. The effectiveness of various interventions used for infants with bronchiolitis remains unclear.
\end{abstract}

Need and purpose: To evaluate the evidence supporting the use of currently available treatment and preventive strategies for infants with bronchiolitis and to provide practical guidelines to the practitioners managing children with bronchiolitis.

Methods: A search of articles published on bronchiolitis was performed using PubMed. The areas of focus were diagnosis, treatment and prevention of bronchiolitis in children. Relevant information was extracted from English language studies published over the last 20 years. In addition, the Cochrane Database of Systematic Reviews was searched.

Results and Conclusions: Supportive care, comprising of taking care of oxygenation and hydration, remains the corner-stone of therapy in bronchiolitis. Pulse oximetry helps in guiding the need for oxygen administration. Several recent evidence-based reviews have suggested that bronchodilators or corticosteroids lack efficacy in bronchiolitis and should not be routinely used. A number of other novel therapies (such as nebulized hypertonic saline, heliox, CPAP, montelukast, surfactant, and inhaled furosemide) have been evaluated in clinical trials, and although most of them did not show any beneficial results, some like hypertonic saline, surfactant, CPAP have shown promising results.

Keywords: Bronchiolitis, CPAP, Epinephrine, Hypertonic saline, Surfactant.

A

cute bronchiolitis is an important cause of morbidity in infants and children. It is the most common cause of hospitalization due to acute lower respiratory tract infection (LRTI) in infants. A number of definitions have been proposed for bronchiolitis: The American Academy of Pediatrics (AAP) defines bronchiolitis as 'acute inflammation, edema and necrosis of epithelial cells lining small airways, increased mucus production, and bronchospasm' [1]; but this definition is of little clinical significance. Another useful definition, which has been used in many clinical studies, is: the first episode of wheezing in a child younger than 12 to 24 months who has physical findings of a viral respiratory infection and has no other explanation for the wheezing, such as pneumonia or atopy [2].

\section{Methods}

A search of articles published on bronchiolitis was performed using PubMed. The areas of focus were diagnosis, treatment and prevention of bronchiolitis in children. Relevant information was extracted from English language studies published over the last 20 years. In addition, the Cochrane Database of Systematic Reviews was searched. We selected relevant articles/ studies/guidelines in various domains for inclusion in this review.

\section{Etiology}

Bronchiolitis is typically caused by a viral infection. With improvement in diagnostic ability to identify viruses in respiratory secretions (nasopharyngeal aspirates) multiple viral agents have been identified as causative agents of acute bronchiolitis: Respiratory syncytial virus (RSV), Rhinovirus, Parainfluenza viruses, Influenza virus, Adenovirus, and Coronavirus. RSV is the most common cause, accounting for $50-80 \%$ cases [3]. In Indian studies, RSV infection was diagnosed in $30-70 \%$ of children with bronchiolitis [4-6]. The proportion of disease caused by specific viruses varies depending upon the season and the year, and there is a wide variation in the reported proportions among various studies. Most of the studies implicate rhinovirus (which normally causes common cold) as the second most common cause of bronchiolitis. Molecular diagnostic techniques have also revealed a high frequency (15-25\%) of mixed viral infections among children evaluated for bronchiolitis [7-11].

Apart from the above mentioned viruses, newer respiratory viruses have been described in children, including human metapneumovirus (hMPV) and human bocavirus (HBoV) [12]. Some of the recent studies have found hMPV as a common cause of respiratory tract infections in children throughout the world [13] and 
often second only to RSV as a cause of bronchiolitis in infants. In contrast to hMPV, the role of $\mathrm{HBoV}$ in causing respiratory illnesses is less clear. This is because $\mathrm{HBoV}$ is associated with high coinfection rate (50-60\%), and therefore the role that $\mathrm{HBoV}$ alone plays in illness can be questioned. Another problem with $\mathrm{HBoV}$ is its lack of cultivability and hence lack of appropriate models for pathogenesis [12].

\section{EPIDEMIOLOGY}

Bronchiolitis typically affects children younger than two years with a peak incidence between two and six months of age. In a prospective hospital-based study from Southern India, of 114 children with bronchiolitis, 87 (76\%) were less than 1 year and 107 (94\%) were less than 2 years of age [14]. Bronchiolitis occurs in epidemics during winter months. In India, outbreaks occur from September to March.

\section{Clinical Presentation}

Children with bronchiolitis typically present with a viral upper respiratory prodrome comprising of rhinorrhea, cough, and on occasion, a low grade fever. The onset of these symptoms is acute. Within 1-2 days of these prodromal symptoms, the cough worsens and child may also develop rapid respiration, chest retractions, and wheezing. The infant may show irritability, poor feeding, and vomiting. Though, in majority of cases, the disease remains mild and recovery starts in 3-5 days, some of these children may continue to worsen.

The importance of a detailed clinical assessment of these children cannot be overemphasized. The components of this assessment include, in-depth review of the child's symptoms, impact of these symptoms on his feeding (respiratory distress often prevents adequate oral fluid intake and causes dehydration), assessment of the child's responsiveness and alertness, identification of various co-morbidities like underlying chronic lung disease, congenital heart disease or immunocompromised state, and complete physical examination. Most of the children with bronchiolitis have tachycardia and tachypnea. Pulse oximetry helps us in deciding about the need for supplemental oxygen. The chest may appear hyper-expanded and may be hyperresonant to percussion. Wheezes and fine crackles may be heard throughout the lungs. Severely affected patients have grunting, marked retractions. They may be cyanosed, and may have impaired perfusion. Apnea may occur in those born prematurely and in younger than two months of age (15). Other associated problems that may occur in children with bronchiolitis include conjunctivitis, otitis media and pharyngitis.

\section{Disease Course and Prediction of Severity}

Bronchiolitis usually is a self-limited disease. Although symptoms may persist for several weeks, the majority of children who do not require hospital admission may continue to have low grade symptoms upto 4 weeks [16]. In previously healthy infants, the average length of hospitalization is three to four days [17]. The course may be prolonged in younger infants and those with comorbid conditions (e.g., chronic lung disease).

A number of risk factors and clinical findings have been proposed to predict the severity of disease in children with bronchiolitis (Table I). Various studies and treatment trials have also used clinical scores (e.g., the Respiratory Distress Assessment Instrument) to predict the disease severity in children with bronchiolitis, but none of these scores have been validated for clinical predictive value in bronchiolitis. It should be emphasized that repeated observation over a period of time may provide a more valid overall assessment of the disease severity than a single examination [1]. Risk factors for mortality include: younger age ( $<6$ months), prematurity, underlying chronic lung disease, cyanotic heart disease or immunocompromised state [24].

\section{TABLE I Predictors of SEVERE Bronchiolitis}

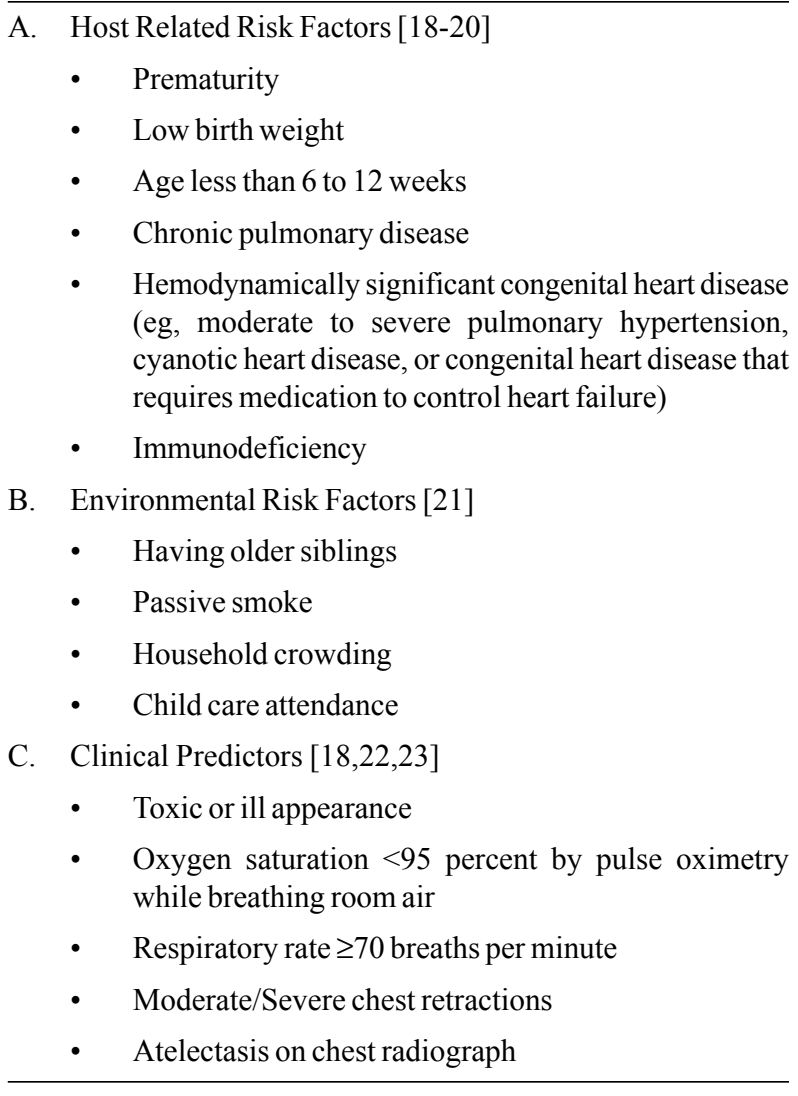




\section{BASELINE WORK-UP}

The diagnosis of bronchiolitis and the assessment of disease severity should be based on history and physical examination. Laboratory tests and radiographs are not required and do not alter treatment decisions [1].

\section{Radiographs}

The radiographic abnormalities of bronchiolitis are variable and include hyperinflation and peribronchial thickening. Patchy atelectasis may result from airway narrowing and mucus plugging. In a prospective study involving 265 children (age 2-23 months) with bronchiolitis, routine radiography identified findings inconsistent with bronchiolitis in only 2 cases, and in neither case did these findings affect the acute management. In fact, radiographic review promoted unnecessary use of antibiotics [25]. Results of this study highlight that radiographs do not change the management of acute bronchiolitis. A chest X-ray may be obtained if the diagnosis is in doubt, co-morbidity like chronic lung disease or heart disease is suspected, there is no improvement or if the child is severely ill [1].

\section{Laboratory tests}

Laboratory tests are not routinely indicated in the evaluation of infants and young children with suspected bronchiolitis. Abnormalities in total and differential white blood cell counts do not predict serious bacterial infection in infants and young children hospitalized with lower respiratory tract infection due to RSV [26].

Measurement of lactate dehydrogenase (LDH) concentration in the nasal-wash fluid has been proposed as an objective indicator of bronchiolitis severity; increased values (suggestive of a robust antiviral response) have been shown to be associated with decreased risk of hospitalization [27]. This observation needs further validation before nasal wash $\mathrm{LDH}$ measurement is used to make decisions regarding hospitalization for children with bronchiolitis.

\section{Virologic testing}

Clinical course, treatment and outcome of acute bronchiolitis due different viral infections are similar; therefore, identification of viral agents does not affect management in the majority of patients. However, in the hospital setting, determining the responsible virus may help to avoid unnecessary antibiotic use and also prevent nosocomial transmission to other patients.

The available tools for etiologic diagnosis include Antigen detection, Immunofluorescence, Polymerase Chain Reaction (PCR), and culture of respiratory secretions obtained by nasal wash or nasal aspirate. New techniques such as real-time polymerase chain reaction (PCR), nested PCR, and multiplex PCR have improved the virologic diagnosis of bronchiolitis immensely $[5,28$, 29]. In a study to detect RSV in children $<2$ years with acute respiratory tract illness using three different techniques: viral culture, direct immunofluorescence, and nested PCR, it was found that PCR was the most sensitive technique ( $11.1 \%$ positivity), followed by direct immunofluorescence $(7.9 \%$ positivity) and viral culture (6.3\% positivity) [30].

\section{THERAPY}

Acute bronchiolitis is, in the majority of cases, a mild and self-limiting illness that can be managed on ambulatory basis with supportive care alone. Management mainly consists of educating parents or caregivers about adequate feeding and to report any deterioration (such as increasing difficulty in breathing, chest indrawing or problems with feeding) to an appropriate health care facility. Multiple intervention studies have been carried out to improve treatment of bronchiolitis. Still there is much controversy, confusion, and lack of evidence over

TABLE II Summary OF InTERVEntions Used For Management of ACute BRonchiolitis

Interventions with clear evidence of effectiveness

- Supportive care (supplemental oxygen, IV fluids)

Interventions which are possibly effective

- Nebulized bronchodilators (epinephrine/salbutamol)

- Nebulized Hypertonic saline

- Dexamethasone + Inhaled epinephrine

Interventions which are possibly effective for most severe cases

- CPAP

- Surfactant

- Heliox

- Aerosolized Ribavirin

Interventions which are possibly ineffective

- Oral bronchodilators

- Montelukast

- Inhaled/Systemic corticosteroids

- Chest physiotherapy

- Antibiotics

- Steam inhalation

- RSV polyclonal immunoglobulin / Palivizumab

- Inhaled Furosemide/Inhaled interferon alfa-2a / Inhaled recombinant human DNase 
the best treatment for infants hospitalised with moderate to severe bronchiolitis [31] (Table II).

\section{Supportive Care}

Supportive care remains the cornerstone of treatment of children with bronchiolitis. It includes maintenance of adequate hydration, provision of respiratory support as necessary, and monitoring for disease progression.

\section{A. Fluid administration}

Children with bronchiolitis are at an increased risk of dehydration because of their increased needs (related to fever and tachypnea) and reduced oral acceptance. Clinicians should carefully assess hydration and ability to take fluids orally. Children having dehydration or difficulty in feeding safely because of respiratory distress should be given intravenous fluids [1]. For children who can tolerate enteral feedings, small frequent feedings or orogastric or nasogastric feedings may be used to prevent dehydration. Children with bronchiolitis are also at an increased risk of fluid retention (and subsequent pulmonary congestion) due to excessive antidiuretic hormone production, so urine output should be carefully monitored [1,32].

\section{B. Nasal Decongestion}

Saline nose drops and cleaning of nostrils by gentle suction may help to relieve nasal block. Instilling saline drops and cleaning nostrils by gentle suction before feeding may be helpful. Parents should be educated about instilling saline drops and cleaning secretions from nose before discharge from hospital [33].

\section{Respiratory support}

\section{Supplemental oxygen}

The major consequence of airway obstruction and concomitant poor distribution of ventilation and perfusion in bronchiolitis is hypoxemia. Humidified oxygen should be administered to hypoxemic infants by any technique familiar to the nursing personnel (nasal cannula, face mask, or head box). Pulse oximetry is the most commonly used tool to decide about oxygen supplementation. The cut-off level of oxyhemoglobin saturation $\left(\mathrm{SpO}_{2}\right)$, at which supplementation should be started or stopped varies widely among different guidelines and different centres. Data are lacking to support the use of a specific $\mathrm{SpO}_{2}$ cut-off value $[1,33]$. In the most recent clinical practice guideline of the American Academy of Pediatrics (AAP) [1], the following options (options define courses that may be taken when either the quality of evidence is suspect or carefully performed studies have shown little clear advantage to one approach over another) are presented:

'Supplemental oxygen is indicated if $\mathrm{SpO}_{2}$ falls persistently below $90 \%$ in previously healthy infants. Oxygen may be discontinued if $\mathrm{SpO}_{2}$ is at or above $90 \%$ and the infant is feeding well and has minimal respiratory distress.'

As the child's clinical course improves, continuous measurement of $\mathrm{SpO}_{2}$ is not routinely needed because it leads to unnecessarily prolonged oxygen supplementation and hospital stay [34, 35].

\section{Continous Positive Airway Pressure}

In severe bronchiolitis early intervention in form of continuous positive airway pressure (CPAP) has been used to prevent mechanical ventilation [36]. CPAP helps in recruitment of collapsed alveoli by opening terminal bronchioles. Airway resistance in terminal airways is reduced with CPAP and also there is decreased air trapping, hyperinflation and work of breathing [37]. A systematic review in 2011 on use of CPAP in acute bronchiolitis concluded that the evidence supporting the use of CPAP to reduce $\mathrm{PCO}_{2}$ and respiratory distress in bronchiolitis was of low methodological quality, and there was no conclusive evidence that CPAP reduced the need for intubation [36]. However, a recent randomised trial comparing nasal CPAP and oxygen inhalation concluded that CPAP resulted in rapid reduction in work of breathing and improvement in the respiratory distress score at 6 hour. The improvement was proportional to the initial severity, suggesting that, early use of CPAP in severe forms of the disease may be beneficial [38]. CPAP level of $7 \mathrm{~cm}$ of water was associated with greatest improvement [39]. Current evidence is inconclusive regarding routine use of CPAP in children with acute bronchiolitis. More studies with adequate numbers and better quality are required.

\section{Mechanical Ventilation}

The major indications for intubation and mechanical ventilation are clinical deterioration (worsening respiratory distress, listlessness, and poor peripheral perfusion), apnea and/or bradycardia, and hypercarbia. Infants do not usually require intubation for oxygenation alone. In a prospective cohort study done in children admitted with RSV LRTI, approximately $9 \%$ of patients required mechanical ventilation [19]. The median duration of mechanical ventilation is relatively short, about 5 days, but protracted courses of ventilation may be required [40].

\section{Chest Physiotherapy}

Chest physiotherapy clears the excessive respiratory 
secretions, and thus helps to reduce airway resistance, the work of breathing, and enhances gas exchange. Inspite of this theoretical advantage, a systematic review of nine randomized trials concluded that chest physiotherapy using vibration and percussion or passive expiratory techniques did not improve respiratory parameters, reduce supplemental oxygen requirement, or reduce length of hospital stay [41]. The use of chest physiotherapy is discouraged in children with bronchiolitis, because it may increase the distress and irritability of ill infants.

\section{Bronchodilators}

Routine use of bronchodilators in the management of bronchiolitis is debatable. One of the major problems with interventional trials evaluating bronchodilators in infants and children with bronchiolitis is the difficulty in distinguishing bronchiolitis from virus-induced wheezing and asthma. Children in the latter categories, who often respond to bronchodilators (and glucocorticoids), are invariably included in bronchiolitis trials, making it difficult to determine the effects of these medications in children with true viral bronchiolitis.

In a meta-analysis of 28 trials (1912 participants) comparing bronchodilators other than epinephrine (included salbutamol, terbutaline, ipratopium) with placebo, there were no significant differences in improvement in oxygenation, hospitalization rate, or duration of hospitalization. A modest improvement in clinical scores was noted in the treated outpatients; however, this small improvement in clinical scores must be weighed against the costs and adverse effects of bronchodilators [42].

Another meta-analysis of 19 trials (2256 participants) compared nebulized epinephrine with placebo or other bronchodilators [43]. Epinephrine versus placebo among outpatients showed a significant reduction in admissions at Day 1 but not at Day 7 postemergency department visit. Epinephrine versus salbutamol showed no differences among outpatients for admissions at Day 1 or 7 . Although epinephrine was associated with decreased length of stay compared with salbutamol, epinephrine did not decrease length of stay when compared with placebo. This review demonstrated the superiority of epinephrine compared to placebo for short-term outcomes for outpatients, particularly in the first 24 hours of care, but there was no evidence to support the use of epinephrine for inpatients.

Oral bronchodilators should not be used in the management of bronchiolitis. They neither shorten clinical illness nor improve clinical parameters, but are associated with adverse effects (increased heart rate) [44].

Based on the current evidence it is not easy to decide about bronchodilator uses. It is also difficult to distinguish bronchiolitis from viral infection associated wheezing or multi-trigger wheeze. In the latter condition, broncho-dilators may improve clinical outcome. Therefore, we consider a trial of bronchodilator with careful monitoring. Choice of bronchodilator may be based on personal or family history of atopy or asthma; if present, salbutamol inhalation may be given. In absence of it, a trial of epinephrine inhalation may be given. Further doses of either medications may be continued only on documentation of improvement.

\section{Steroids}

\section{Systemic corticosteroids}

Initial studies of the treatment of bronchiolitis with corticosteroids suggested that steroids might favourably influence mortality and morbidity. However, large controlled studies have failed to demonstrate any significant clinical effect. A meta-analysis evaluating the use of systemic glucocorticoids (oral, intramuscular, or intravenous) and inhaled glucocorticoids for acute bronchiolitis in children ( 0 to 24 months of age) included 17 trials with 2596 patients [45]. In pooled analyses, no significant differences were found in hospital admission rate, length of stay, clinical score after 12 hours, or hospital readmission rate. Hence, it is recommended not to use glucocorticoids in healthy infants and young children with a first episode of bronchiolitis. Another meta-analysis (of 3 studies) studied the role of systemic steroids in critically ill children with bronchiolitis [46]. It was found that systemic corticosteroid showed no overall effect on duration of mechanical ventilation.

\section{Corticosteroids plus Epinephrine}

A possibility of synergy between epinephrine and glucocorticoids has also been evaluated. There is one trial which suggested that administration of epinephrine and glucocorticoids in the outpatient setting prevents hospitalization within seven days [47]. In this multicentre trial, there was a reduction in hospitalization rates in the group that received dexamethasone and 2 doses of epinephrine by nebulizer as compared with those who were treated with placebo (17.1\% vs 26.4\%). Number needed to prevent one admission was 11. However, the strength of evidence was low and after adjustment for multiple comparisons, the difference did not reach statistical significance. This may have a potential role in future treatment algorithms. Till additional studies shows similar results and safety is 
established, this combination therapy may be considered under evaluation.

\section{Inhaled Corticosteroids (ICS)}

Use of ICS during acute bronchiolitis has been proposed to prevent post-bronchiolitic wheezing. A systematic review of 5 studies involving 374 infants did not demonstrate an effect of ICS, given during the acute phase of bronchiolitis, in the prevention of recurrent wheezing following bronchiolitis [48]. An additional RCT involving 243 infants with RSV-related LRTI did not find any effect of inhaled corticosteroids on recurrent wheeze [49]. Hence, there is no evidence for use of inhaled corticosteroids to prevent or reduce postbronchiolitis wheezing after RSV bronchiolitis.

\section{Antibiotics}

Unnecessary use of antibiotics is associated with increased cost of treatment, adverse reactions and development of bacterial resistance in community/ geographic region. In children with bronchiolitis and fever, the risk of secondary bacterial infection is low, therefore, routine use of antibiotics is not recommended. It is recommended that antibiotics should be used only in children having specific indications of coexistence of a bacterial infection [1]. Presence of infiltrates or alelectasis on $X$-ray film may not indicate bacterial infection. Clinical setting, with consolidation on $X$-ray film may indicate a possibility of bacterial pneumonia in infants with bronchiolitis [50].

A systematic review including five studies (543 participants) did not find significant benefits for use of antibiotics in acute bronchiolitis. However, the review indicated a need for research to identify a subgroup of patients who may benefit from antibiotics [51]. One small study (21 participants) which was included in this review, compared clarithromycin for 3 weeks with placebo in children with RSV bronchiolitis. Treatment with clarithromycin was associated with reduction in the length of hospital stay, duration of need for oxygen, and readmission rates. Clarithromycin was proposed to have a possible immunomodulatory effect. More wellplanned studies to clarify role of macrolides in acute bronchiolitis are required [52].

\section{Hypertonic Saline}

Aerosolized hypertonic saline has been proposed as a therapeutic modality for acute bronchiolitis. Hypertonic saline may reverse some pathophysiological abnormalities in acute bronchiolitis by decreasing epithelial edema, improving elasticity and viscosity of mucus and thus improving airway clearance. A Cochrane review of seven trials involving 581 infants (282 inpatients, 65 outpatients and 234 emergency department patients) with acute bronchiolitis found that nebulisation with 3\% saline results in a significantly shorter length of hospital stay as well as a lower clinical score as compared to nebulisation with $0.9 \%$ saline [53]. The potential side effects, principally acute bronchospasm, remain a concern with nebulized hypertonic saline. In six of the seven trials included in the above mentioned review, patients received hypertonic saline inhalation in conjunction with bronchodilators and no significant adverse events related to $3 \%$ saline inhalation were reported [54].

A recent randomized controlled trial reported that high volume normal saline was as effective as 3\% saline in children with mild bronchiolitis. It may be inferred that improved clearance of mucus in airway may be function of total mass of $\mathrm{NaCl}$ rather than concentration of $\mathrm{NaCl}$ [55]. Hypertonic saline inhalation may be considered as potential treatment for bronchiolitis. However, there are several unanswered questions related to its use including optimal volume, concentration of saline, frequency of administration and effective device. Its use cannot be recommended till all these are addressed by further studies.

\section{Inhaled Furosemide}

Furosemide inhalation in acute bronchiolitis has been proposed with a hypothesis that it may improve outcome by acting on airway smooth muscle, airway vessels, electrolytes and fluid transport across respiratory mucosa, and reducing airway inflammation. One RCT (32 participants) studied the effect of inhaled furosemide in hospitalized infants with bronchiolitis, and recorded no significant clinical effects in these infants [56]. Therefore, there is no evidence for use of inhaled furosemide in the management of bronchiolitis.

\section{Steam inhalation}

Steam inhalation/ mist inhalation has been proposed to improve airway clearance of mucus and outcome of acute bronchiolitis. Being less expensive and easily available, steam was considered to be a suitable intervention in low income countries. A systematic review could identify only one RCT (156 participants) that compared role of nebulised salbutamol, nebulised saline and mist in a tent in children with acute bronchiolitis. [57,58]. Group of children receiving salbutamol inhalation showed significant improvement in respiratory distress symptom (RDS) score but there was no improvement in children receiving mist in a tent or nebulised saline. In view of limited experience with mist/ steam inhalation, more 
studies are required to prove or disapprove role of steam inhalation in acute bronchiolitis.

\section{Leukotriene receptor antagonists (Montelukast)}

Clinical symptoms and post-bronchiolitis cough and wheeze are attributed to the increased cysteinyl leukotrienes in airway secretions of children with bronchiolitis during acute phase as well as in short term follow up. Randomized trials of montelukast as a treatment for acute bronchiolitis have had conflicting results $[59,60]$. Randomized trials of montelukast for the prevention of airway reactivity and post-bronchiolitis respiratory symptoms have also had inconsistent results $[61,62]$. However, in the largest trial (979 participants), use of montelukast for 24 weeks was not associated with improvement in post-bronchiolitis respiratory symptoms [62]. In view of these studies, montelukast is currently not recommended for treatment of bronchiolitis or for prevention of airway reactivity after bronchiolitis.

\section{Heliox}

Heliox (mixture of helium and oxygen) may improve alveolar ventilation as it flows through airways with less turbulence and resistance. This may reduce work of breathing and improve oxygenation in respiratory illness with moderate to severe airway obstruction including acute bronchiolitis. A meta-analysis of four clinical trials (84 participants), using heliox demonstrated improved respiratory distress scores in first hour in children with moderate to severe acute bronchiolitis. However, heliox inhalation did not affect need for intubation and mechanical ventilation and length of stay in pediatric intensive care unit. There was significant heterogeneity in the included studies [63].

It is concluded that evidence for beneficial role of Heliox in acute bronchiolitis are inadequate and more experience is required [64].

\section{Antivirals}

Ribavirin, a synthetic nucleoside analog resembling guanosine, acts by inhibiting viral protein synthesis, and has a broad antiviral effect. It is delivered as a smallparticle aerosol for 18 to 20 hours per day. The drug is relatively expensive and may lead to some risk (teratogenic effect) to health care personnel administering the drug [1]. A systematic review of 10 RCTs (320 participants) reported no improvement in clinical outcome of acute bronchiolitis after ribavirin use [65]. Ribavirin may be considered in high risk infants (immunocompromised and/or hemodynamically significant cardiopulmonary disease) and in infants requiring mechanical ventilation $[1,46]$.

Apart from ribavarin, no other antiviral is currently approved for use in bronchiolitis. Numerous other drugs are undergoing trials for use against RSV, which is the most common cause of bronchiolitis. The immunosuppressive agent leflunomide has been shown to exert potent antiviral and anti-inflammatory activity against RSV in experimental animal models [66]. Another promising group of drugs currently under investigation are the small molecule fusion inhibitors (TMC353121, CL387626, RFI-641, JNJ-2408068 etc) that inhibit viral fusion by interacting with the RSV F protein (RSV F protein mediates the fusion of viral envelope with host cell membrane) $[67,68]$. Fusion inhibitors have also been shown to be effective against hMPV in experimental animals, and some researchers have suggested a possibility for use of these fusion inhibitors for early treatment in an epidemic context. However, more studies are needed to characterize the best delivery mode, dosage, and schedule of administration for these fusion inhibitors [69].

\section{Surfactant}

In severe bronchiolitis there may be secondary surfactant insufficiency suggesting possible role of administration of exogenous surfactant [64]. A meta-analysis (included three RCTs with total 79 participants) evaluated the effect of exogenous surfactant in infants and children with bronchiolitis requiring mechanical ventilation [70]. The duration of mechanical ventilation and duration of ICU stay were significantly lower in the surfactant group compared to the control group. Use of surfactant had favourable effects on oxygenation and $\mathrm{CO}_{2}$ elimination. No adverse effects and no complications were observed. Current evidence suggests that surfactant therapy may have potential use in acute severe bronchiolitis requiring mechanical ventilation. However, in view of few studies including small numbers of participants, reliable estimates of the effects of surfactant cannot be made. There is a need for larger trials with adequate power and to establish beneficial role of administration of surfactant in infants with severe bronchiolitis.

\section{Prevention of Bronchiolitis}

Acute bronchiolitis is a common infection with significant financial burden on society. There is no effective therapy that can improve outcome if administered early. There is need to develop preventive strategies. The preventive measures include general measures and specific measures (immunoprophylaxis).

\section{General measures}

A careful barrier nursing measures may help in prevention of nosocomial (cross infection) in hospitals and intensive care units. 


\section{Immunoprophylaxis}

Passive immunoprophylaxis using polyclonal or monoclonal antibodies to high risk infants before RSV season has been documented to reduce admission rates in these infants with acute bronchiolitis. However, it is important to note that severe bronchiolitis requiring admission in pediatric intensive care is not restricted to high risk group, rather majority are healthy term infants without risk factors [71].

\section{Polyclonal antibodies}

Polyclonal antibodies containing RSV IgG is prepared from pooled plasma. This is administered by intravenous route before RSV season. The potential disadvantages associated with polyclonal antibodies include: need for intravenous access; risk of transmission of blood-borne infections, possible interference with antibody response to routine immunization specifically live vaccines. [71]. It has also been evaluated for treatment of acute bronchiolitis without success [72].

\section{Monoclonal antibodies}

Palivizumab is a humanized mouse IgG1 monoclonal antibody directed against site A and F glycoprotein of RSV. It blocks the fusion of the virus to the host epithelial cell. It reduces RSV infection associated hospitalization in high risk infants but does not reduce mortality rates [1]. Economic analysis of prophylactic administration of palivizumab have failed to show savings in the net cost due to very high cost of palivizumab. The 2006 Report of the Committee on Infectious Disease (Red Book) includes the following indications for the use of palivizumab [73]:

1. Children younger than 24 months of age with chronic lung disease (CLD) of prematurity who have required medical therapy for CLD within 6 months before the start of the RSV season.

2. Infants born at 28 weeks of gestation or earlier who are younger than 12 months of age at the start of the RSV season.

3. Infants born at 29 to 32 weeks of gestation who are younger than 6 months of age at the start of the RSV season.

4. Infants born between 32 and 35 weeks of gestation, who are younger than 6 months of age at the start of the RSV season and have 2 or more of the following risk factors: child care attendance, school-aged siblings, exposure to environmental air pollutants, congenital abnormalities of the airways, or severe neuromuscular disease.
5. Children who are 24 months of age or younger with hemodynamically significant cyanotic and acyanotic congenital heart disease. This includes infants who are receiving medication to control congestive heart failure, infants with moderate to severe pulmonary hypertension, and infants with cyanotic heart disease.

Palivizumab is administered intramuscularly at a dose of $15 \mathrm{mg} / \mathrm{kg}$ monthly (every 30 days) during the RSV season. A maximum of 5 doses is generally sufficient prophylaxis during one season [74]. Once a child qualifies for prophylaxis, administration should continue throughout the RSV season and not stop at the point he or she reaches any certain age. Palivizumab can be given with routine immunizations since it does not interfere with the immunologic response to vaccines. Palivizumab is not associated with an increased risk of localized or systemic adverse events.

Other monoclonal antibody (mAb) variants, which are derived from palivizumab are being evaluated in clinical trials for immunoprophylaxis. These include Motavizumab, a second-generation mAb, and NumaxYTE, a third-generation mAb. The advantage of NumaxYTE is its extended half-life, thus obviating the need for monthly treatments [71].

\section{Conclusions}

Bronchiolitis is a common respiratory tract infection in infancy; the commonest etiologic agent being the respiratory syncytial virus. The diagnosis of bronchiolitis is mostly clinical, and laboratory investigations have a limited role in diagnosis and management. The current management primarily consists of supportive care, including hydration, supplemental oxygen, and mechanical ventilation when required. At this point, there is no specific treatment for bronchiolitis for which there is a strong or convincing evidence of effectiveness. It may be appropriate to administer nebulized epinephrine or salbutamol in a given child and continue these if found beneficial and discontinue if there is no effect. Corticosteroids are judged to be ineffective and not indicated for these infants. In absence of an effective vaccine, Palivizumab, a monoclonal antibody against RSV may be considered for passive immunoprophylaxis in certain high risk infants before the RSV season.

Contribution: All authors were involved in literature search, manuscript writing and revisions. SKK will act as guarantor. Funding: None; Conflict of interest: None stated.

\section{REFERENCES}

1. American Academy of Pediatrics Subcommittee on Diagnosis and Management of Bronchiolitis. Diagnosis 
and management of bronchiolitis. Pediatrics. 2006;118:1774-93.

2. Hanson IC, Shearer WT. Bronchiolitis. In: McMillan JA, Feigin RD, DeAngelis C, Jones MD, eds. Oski's Pediatrics: Principles and Practice, 4th ed. Philadelphia: Lippincott Williams \& Wilkins; 2006. p.1391.

3. Wright AL, Taussig LM, Ray CG, Harrison HR, Holberg CJ. The Tucson Children's Respiratory Study II. Lower respiratory tract illness in the first year of life. Am J Epidemiol. 1989;129:1232-64.

4. Gupta S, Shamsundar R, Shet A, Chawan R, Srinivasa H. Prevalence of respiratory syncytial virus infection among hospitalized children presenting with acute lower respiratory tract infections. Indian $\mathrm{J}$ Pediatr. 2011;78:1495-7.

5. Bharaj P, Sullender WM, Kabra SK, Mani K, Cherian J, Tyagi $\mathrm{V}$, et al. Respiratory viral infections detected by multiplex PCR among pediatric patients with lower respiratory tract infections seen at an urban hospital in Delhi from 2005 to 2007. Virol J. 2009;26:89

6. Maitreyi RS, Broor S, Kabra SK, Ghosh M, Seth P, Dar L, et al. Rapid detection of respiratory viruses by centrifugation enhanced cultures from children with acute lower respiratory tract infections. J Clin Virol. 2000;16:41-7.

7. Banerjee S, Bharaj P, Sullender W, Kabra SK, Broor S. Human metapneumovirus infections among children with acute respiratory infections seen in a large referral hospital in India. J Clin Virol. 2007;38:70-2.

8. Bharaj P, Sullender WM, Kabra SK, Broor S. Human bocavirus infection in children with acute respiratory tract infection in India. J Med Virol. 2010;82:812-6.

9. Stempel HE, Martin ET, Kuypers J, Englund JA, Zerr DM. Multiple viral respiratory pathogens in children with bronchiolitis. Acta Paediatr. 2009; 98:123-6.

10. Zorc JJ, Hall CB. Bronchiolitis: Recent evidence on diagnosis and management. Pediatrics. 2010;125:342-9.

11. Canducci F, Debiaggi M, Sampaolo M, Marinozzi MC, Berrè $\mathrm{S}$, Terulla $\mathrm{C}$, et al. Two-year prospective study of single infections and co-infections by respiratory syncytial virus and viruses identified recently in infants with acute respiratory disease. J Med Virol. 2008;80:71623.

12. Milder E, Arnold JC. Human metapneumovirus and human bocavirus in children. Pediatr Res. 2009;65:78R83R.

13. Williams JV, Harris PA, Tollefson SJ, Halburnt-Rush LL, Pingsterhaus JM, Ed-wards KM, et al. Human metapneumovirus and lower respiratory tract disease in otherwise healthy infants and children. N Engl J Med. 2004;350:443-50.

14. Cherian T, Simoes EA, Steinhoff MC, Chitra K, John M, Raghupathy $\mathrm{P}$, et al. Bronchiolitis in tropical South India. Am J Dis Child. 1990;144:1026-30.

15. Kneyber MC, Brandenburg AH, de Groot R, Joosten KF, Rothbarth $\mathrm{PH}$, Ott A, et al. Risk factors for respiratory syncytial virus associated apnoea. Eur J Pediatr. 1998;157:331-5.

16. Swingler GH, Hussey GD, Zwarenstein M. Duration of illness in ambulatory children diagnosed with bronchiolitis. Arch Pediatr Adolesc Med. 2000;154:9971000.

17. Shay DK, Holman RC, Newman RD, Liu LL, Stout JW, Anderson LJ. Bronchiolitis-associated hospitalizations among US children, 1980-1996. JAMA. 1999;282: 1440-6.

18. Shaw KN, Bell LM, Sherman NH. Outpatient assessment of infants with bronchiolitis. Am J Dis Child. 1991;145:151-5.

19. Wang EE, Law BJ, Stephens D. Pediatric Investigators Collaborative Network on Infections in Canada (PICNIC) prospective study of risk factors and outcomes in patients hospitalized with respiratory syncytial viral lower respiratory tract infection. J Pediatr. 1995;126:212-9.

20. Meissner HC. Selected populations at increased risk from respiratory syncytial virus infection. Pediatr Infect Dis J. 2003;22:S40-44.

21. McConnochie KM, Roghmann KJ. Parental smoking, presence of older siblings, and family history of asthma increase risk of bronchiolitis. Am J Dis Child. 1986;140:806-12.

22. Voets S, van Berlaer G, Hachimi-Idrissi S. Clinical predictors of the severity of bronchiolitis. Eur J Emerg Med. 2006;13:134-8.

23. Mansbach JM, Clark S, Christopher NC, LoVecchio F, Kunz S, Acholonu U, et al. Prospective multicenter study of bronchiolitis: predicting safe discharges from the emergency department. Pediatrics. 2008;121:680-8.

24. Thorburn K. Pre-existing disease is associated with a significantly higher risk of death in severe respiratory syncytial virus infection. Arch Dis Child. 2009; 94:99-103.

25. Schuh S, Lalani A, Allen U, Manson D, Babyn P, Stephens D, et al. Evaluation of the utility of radiography in acute bronchiolitis. J Pediatr. 2007;150:429-33.

26. Purcell K, Fergie J. Lack of usefulness of an abnormal white blood cell count for predicting a concurrent serious bacterial infection in infants and young children hospitalized with respiratory syncytial virus lower respiratory tract infection. Pediatr Infect Dis J. 2007; 26:311-15.

27. Laham FR, Trott AA, Bennett BL, Kozinetz CA, Jewell AM, Garofalo RP, et al. LDH concentration in nasal-wash fluid as a biochemical predictor of bronchiolitis severity. Pediatrics. 2010;125:e225-33.

28. Ong GM, Wyatt DE, O’Neill HJ, McCaughey C, Coyle $\mathrm{PV}$. A comparison of nested polymerase chain reaction and immunofluorescence for the diagnosis of respiratory in children with bronchiolitis. J Hosp Infect. 2001;49:122-8.

29. Hguenin A, Moutte L, Renois F, Leveque N, Talmud D, Abely $\mathrm{M}$, et al. Broad respiratory virus detection in infants hospitalized for bronchiolitis by use of a multiplex RT-PCR DNA microarray system. J Med Virol.2012;84: 79-85.

30. Reis AD, Fink MCD, Machado CM, Paz Jr(I) JP, Oliveira $\mathrm{RR}$, Tateno AF, et al. Comparison of direct immunofluorescence, conventional cell culture and polymerase 
chain reaction techniques for detecting respiratory syncytial virus in nasopharyngeal aspirates from infants. Rev Inst Med Trop S Paulo. 2008;50:37-40.

31. Smyth RL, Openshaw PJ. Bronchiolitis. Lancet. 2006;368:312-22.

32. van Steensel-Moll HA, Hazelzet JA, van der Voort E, Neijens HJ, Hackeng WH. Excessive secretion of antidiuretic hormone in infections with respiratory syncytial virus. Arch Dis Child. 1990;65:1237-9.

33. Steiner RWP. Treating acute bronchiolitis associated with RSV. Am Family Physician. 2004;69:325-30.

34. Schroeder AR, Marmor AK, Pantell RH, Newman TB. Impact of pulse oximetry and oxygen therapy on length of stay in bronchiolitis hospitalizations. Arch Pediatr Adolesc Med. 2004;158:527-30.

35. Unger S, Cunningham S. Effect of oxygen supplementation on length of stay for infants hospitalized with acute viral bronchiolitis. Pediatrics. 2008;121:470-5.

36. Donlan M, Fontela PS, Puligandla PS. Use of continuous positive airway pressure (CPAP) in acute viral bronchiolitis: A systematic review. Pediatr Pulmonol. 2011;46:736-46.

37. Smith TC, Marini JJ. Impact of PEEP on lung mechanics and work of breathing in severe airflow obstruction. $\mathrm{J}$ Appl Physiol. 1988;65:1488-99.

38. Mile'si C, Matecki S, Jaber S, Mura T, Jacquot A, Pidoux $\mathrm{O}$, et al. $6 \mathrm{~cm} \mathrm{H} 2 \mathrm{O}$ continuous positive airway pressure versus conventional oxygen therapy in severe viral bronchiolitis: A randomized trial. Pediatr Pulmonol. 2013;48:45-51.

39. Essouri S, Durand P, Chevret L, Balu L, Devictor D, Fauroux B, et al. Optimal level of nasal continuous positive airway pressure in severe viral bronchiolitis. Intensive Care Med. 2011;37:2002-7.

40. Wohl MEB. Bronchiolitis. In: Chernick V, Boat TF, Wilmott RW, Bush A, editors. Kendig's Disorders of the Respiratory Tract in Children. $6^{\text {th }}$ ed. Philadelphia: Saunders Elsevier Publishers; 1998. P. 423-32.

41. Roqué i Figuls M, Giné-Garriga M, Granados Rugeles C, Perrotta C. Chest physiotherapy for acute bronchiolitis in paediatric patients between 0 and 24 months old. Cochrane Database Syst Rev. 2012;2:CD004873.

42. Gadomski AM, Brower M. Bronchodilators for bronchiolitis. Cochrane Database Syst Rev. 2010;12:CD001266.

43. Hartling L, Bialy LM, Vandermeer B, Tjosvold L, Johnson DW, Plint AC, et al. Epinephrine for bronchiolitis. Cochrane Database Syst Rev. 2011;6:CD003123.

44. Patel H, Gouin S, Platt RW. Randomized, double-blind, placebo-controlled trial of oral albuterol in infants with mild-to-moderate acute viral bronchiolitis. J Pediatr. 2003;142:509-14.

45. Fernandes RM, Bialy LM, Vandermeer B, Tjosvold L, Plint AC, Patel H, et al. Glucocorticoids for acute viral bronchiolitis in infants and young children. Cochrane Database Syst Rev. 2010;10:CD004878.

46. Davison C, Ventre KM, Luchetti M, Randolph AG. Efficacy of interventions for bronchiolitis in critically ill infants: A systematic review and meta-analysis. Pediatr Crit Care Med. 2004;5:482-9.

47. Plint AC, Johnson DW, Patel H, Wiebe N, Correll R, Brant R, et al. Epinephrine and dexamethasone in children with bronchiolitis. N Engl J Med. 2009;360:2079-89.

48. Blom DJM, Ermers M, Bont L, van Woensel JBM, van Aalderen WMC. Inhaled corticosteroids during acute bronchiolitis in the prevention of post-bronchiolitic wheezing. Cochrane Database Syst Rev. 2007;1:CD004881.

49. Ermers MJJ, Rovers MM, van Woensel JB, Kimpen JLL, Bont LJ, on behalf of the RSV Corticosteroid Study Group. The effect of high dose inhaled corticosteroids on wheeze in infants after respiratory syncytial virus infection: randomised double blind placebo controlled trial. BMJ. 2009;338:b897.

50. Davies HD, Matlow A, Petric M, Glazier R, Wang EE. Prospective comparative study of viral, bacterial and atypical organisms identified in pneumonia and bronchiolitis in hospitalized Canadian infants. Pediatr Infect Dis J. 1996;15:371-5.

51. Spurling GK, Doust J, Del Mar CB, Eriksson L. Antibiotics for bronchiolitis in children. Cochrane Database Syst Rev. 2011;6:CD005189.

52. Tahan F, Ozcan A, Koc N. Clarithromycin in the treatment of RSV bronchiolitis: a double-blind, randomised, placebo-controlled trial. Eur Respir J. 2007;29:91-7.

53. Zhang L, Mendoza-Sassi RA, Wainwright C, Klassen TP. Nebulized hypertonic saline solution for acute bronchiolitis in infants. Cochrane Database Syst Rev. 2008;4:CD006458.

54. Luo Z, Liu E, Luo J, Li S, Zeng F, Yang X, et al. Nebulized hypertonic saline/salbutamol solution treatment in hospitalized children with mild to moderate bronchiolitis. Pediatr Int. 2010;52:199-202.

55. Anil AB, Anil M, Saglam AB, Cetin N, Bal A, Aksu N. High volume normal saline alone is as effective as nebulized salbutamol-normal saline, epinephrine-normal saline, and $3 \%$ saline in mild bronchiolitis. Pediatr Pulmonol. 2010;45:41-7.

56. Bar A, Srugo I, Amirav I, Tzverling C, Naftali G, Kugelman A. Inhaled furosemide in hospitalized infants with viral bronchiolitis: A randomized, double-blind, placebo-controlled pilot study. Pediatr Pulmonol. 2008;43:261-7.

57. Umoren R, Odey F, Meremikwu MM. Steam inhalation or humidified oxygen for acute bronchiolitis in children up to three years of age. Cochrane Database Syst Rev. 2011;1: CD006435.

58. Can D, Inan G, Yendur G, Oral R, Gunay I. Salbutamol or mist in acute bronchiolitis. Acta Paediatrica Japonica. 1998;40:252-5.

59. Amirav I, Luder AS, Kruger N, Borovitch Y, Babai I, Miron $\mathrm{D}$, et al. A double-blind, placebo-controlled, randomized trial of montelukast for acute bronchiolitis. Pediatrics. 2008; 122:e1249-55.

60. Zedan M, Gamil N, El-Assmy M, Fayez E, Nasef N, Fouda A, et al. Montelukast as an episodic modifier for acute viral bronchiolitis: a randomized trial. Allergy 
Asthma Proc. 2010;31:147-53.

61. Kim CK, Choi J, Kim HB, Callaway Z, Shin BM, Kim JT, et al. A randomized intervention of montelukast for postbronchiolitis: effect on eosinophil degranulation. J Pediatr. 2010;156:749-54.

62. Bisgaard H, Flores-Nunez A, Goh A, Azimi P, Halkas A, Malice MP, et al. Study of montelukast for the treatment of respiratory symptoms of post-respiratory syncytial virus bronchiolitis in children. Am J Respir Crit Care Med. 2008;178:854-60.

63. Liet JM, Ducruet T, Gupta V, Cambonie G. Heliox inhalation therapy for bronchiolitis in infants. Cochrane Database Syst Rev. 2010;4:CD006915.

64. Eber E. Treatment of acute viral bronchiolitis. Open Microbiol J. 2011;5:159-64.

65. King VJ, Viswanathan M, Bordley WC, Jackman AM, Sutton SF, Lohr KN, et al. Pharmacologic treatment of bronchiolitis in infants and children. Arch Pediatr Adolesc Med. 2004;158:127-37.

66. Dunn MC, Knight DA, Waldman WJ. Inhibition of respiratory syncytial virus in vitro and in vivo by the immunosuppressive agent leflunomide. Antivir Ther. 2011;16:309-17.

67. Olszewska W, Ispas G, Schnoeller C, Sawant D, Van de Casteele T, Nauwelaers D, et al. Antiviral and lung protective activity of a novel respiratory syncytial virus fusion inhibitor in a mouse model. Eur Respir J. 2011;38:401-8.
68. Douglas JL, Panis ML, Ho E, Lin KY, Krawczyk SH, Grant DM, et al. Small Molecules VP-14637 and JNJ2408068 Inhibit Respiratory Syncytial Virus Fusion by Similar Mechanisms. Antimicrobial Agents Chemoth. 2005;49:2460-6.

69. Deffrasnes C, Hamelin M, Prince GA, Boivin G. Identification and Evaluation of a Highly Effective Fusion Inhibitor for Human Metapneumovirus. Antimicrobial Agents Chemoth. 2008;52:279-87.

70. Jat KR, Chawla D. Surfactant therapy for bronchiolitis in critically ill infants. Cochrane Database Syst Rev. 2012;9:CD009194.

71. Mejías A, Ramilo O. Review of palivizumab in the prophylaxis of respiratory syncytial virus (RSV) in highrisk infants. Biologics. 2008;2:433-9.

72. Fuller HL, Del Mar CB. Immunoglobulin treatment for respiratory syncytial virus infection. Cochrane Database Syst Rev. 2006;4:CD004883.

73. American Academy of Pediatrics. Red Book: 2006 Report of the Committee on Infectious Diseases. 27th ed. Elk Grove Village, IL: American Academy of Pediatrics; 2006.

74. American Academy of Pediatrics Committee on Infectious Diseases and Committee on Fetus and Newborn. 2003. Revised indications for the use of palivizumab and respiratory syncytial virus immune globulin intravenous for the prevention of respiratory syncytial virus infections. Pediatrics. 2003;112:1442-6. 